\title{
Article \\ Could Gnomoniopsis castaneae Be Used as a Biological Control Agent against Insect Pests?
}

\author{
Spiridon Mantzoukas ${ }^{1, *}$, Ioannis Lagogiannis ${ }^{1}$, Aristeidis Ntoukas ${ }^{1}$, George T. Tziros ${ }^{2}$, \\ Konstantinos Poulas ${ }^{1}\left(\mathbb{D}\right.$, Panagiotis A. Eliopoulos ${ }^{3}\left[\right.$ and Dimitrios N. Avtzis $\left.{ }^{2, *} * \mathbb{(}\right)$ \\ 1 Department of Pharmacy, University of Patras, 26504 Patras, Greece; lagoipp@gmail.com (I.L.); \\ ntoukasaris7@gmail.com (A.N.); kpoulas@upatras.gr (K.P.) \\ 2 Forest Research Institute, Hellenic Agricultural Organization Demeter, Vassilika, 57006 Thessaloniki, Greece; \\ gtziros@yahoo.gr \\ 3 Department of Agrotechnology, University of Thessaly, Gaiopolis, 41500 Larissa, Greece; eliopoulos@uth.gr \\ * Correspondence: mantzoukas@upatras.gr (S.M.); dimitrios.avtzis@fri.gr (D.N.A.)
}

Citation: Mantzoukas, S.;

Lagogiannis, I.; Ntoukas, A.; Tziros,

G.T.; Poulas, K.; Eliopoulos, P.A.;

Avtzis, D.N. Could Gnomoniopsis castaneae Be Used as a Biological Control Agent against Insect Pests? Appl. Sci. 2021, 11, 4066. https:// doi.org/10.3390/app11094066

Academic Editor: Paola Grenni

Received: 5 March 2021

Accepted: 26 April 2021

Published: 29 April 2021

Publisher's Note: MDPI stays neutral with regard to jurisdictional claims in published maps and institutional affiliations.

Copyright: (c) 2021 by the authors. Licensee MDPI, Basel, Switzerland. This article is an open access article distributed under the terms and conditions of the Creative Commons Attribution (CC BY) license (https:// creativecommons.org/licenses/by/ $4.0 /)$.

\begin{abstract}
Gnomoniopsis castaneae is the cause of the chestnut brown rot but has been also regarded as an important mortality factor for the chestnut gall wasp Dryocosmus kuriphilus. The question to whether G. castaneae could serve as a natural biocontrol agent against insect pests is investigated in the present study. We used three serious insect pests as experimental model insects: Plodia interpuctella and Trogoderma granarium, which are important pests of stored products, and Myzus persicae, a cosmopolitan, serious pest of annual and perennial crop plants. Although chemical pesticides represent effective control means, they are also related to several environmental and health risks. In search for alternative pest management methods, scientific interest has been focused, inter alia, on the use of entomopathogenic fungi. While Isaria fumosorosea has long been recognized as an effective control agent against several pests, G. castaneae has been very little studied. The present study examined whether and to what extent G. castaneae and I. fumosorosea exhibit insecticidal activity against fourth-instar larvae of $P$. interpunctella and T. granarium and adults of $M$. persicae. Mortality was examined in interrelation with dosage and time exposure intervals. Both fungi exhibited pesticidal action. However, G. castaneae induced noteworthy mortality only at very high doses. In general, we concluded that $G$. castaneae failed to cause high insect pathogenicity at normal doses and may not be an efficient biocontrol agent compared with other entomopathogens. On the other hand, our study reiterates the pathogenic potential of I. fumosorosea. More studies are needed to further our insight into the potential of EF species as a component of IPM.
\end{abstract}

Keywords: biocontrol; Gnomoniopsis castaneae; Isaria fumosorosea; P. interpunctella; T. granarium; M. persicae; survival time

\section{Introduction}

Entomopathogenic fungi (EPF) make up a specialized group of fungi which comprise numerous genotypes [1]. Within the framework of the biocontrol of insect pests in field crops and storage facilities, EPF fungi have attracted extensive interest in recent years [2]. EPFs inhabit a wide range of dwellings including urban environments, meadow land, dry, and agricultural places. They demonstrate high virulence against many insects and have minimal residual effects.

Insect pathogens have a biological cycle that is synchronized with that of the host but also adapted to the prevailing environmental conditions [3]. Infection can be restricted by low levels of relative humidity, shortage of nutrients in the cuticle, as well as the inability to recognize the host due to the absence of contributing factors $[4,5]$. The degree of the infection depends on the infectivity of the fungus, the defensive resilience of the insect, and several other biological and abiotic factors [3]. In the 1990s, Isaria fumosorosea Wize 
(Hypocreales: Clavicipitaceae) was reported as the most common entomopathogenic fungus in Asia, Russia, the USA, South America, and India, infecting Bemisia spp. (Hemiptera: Sternorrhyncha) and Trialeurodes vaporariarum (Hemiptera: Sternorrhyncha) [6]. Depending on the strain, I. fumosorosea has a wide range of hosts and could be effective against several insect pests [7-10]. For example, it has been proved highly effective against Plutella $x y$ lostella L. (Lepidoptera: Plutellidae) [11-13]. In addition, it has been commercially available all over the world [14].

On the other hand, Gnomoniopsis castaneae G. Tamietti (Sordariomycetes: Gnomoniaceae) has been recognized as the cause of the chestnut brown rot in Europe and Australasia [15-18]. The chestnut brown rot which has appeared in several chestnut areas around the world, could be the most threatening disease of chestnuts, causing losses to post-harvest yields as high as 60-70\% [19]. Additionally, G. castaneae causes chestnut canker symptoms in several countries worldwide $[20,21]$. While its origin has not been definitively established yet, G. castaneae is a cryptic species which has been reported in Australasia and India on Japanese (Castanea crenata Sieb. Zucc. (Angiosperms: Fagales) and European (C. sativa Mill.) chestnut.

G. castaneae exists endophytically in most chestnut organs and tissues, in an asymptomatic manner unless favorable environmental conditions trigger its emergence [22,23]. For instance, the chestnut brown rot is aggravated by rainfall during flowering [24], most probably because flowers are infected by ascospores dispersed from dead burrs in the orchard [18]. In Italy and Switzerland, a noteworthy aggravation of chestnut brown rot took place after the invasion of the Dryocosmus kuriphilus Yasumatsu (Hymenoptera: Cynipidae) chestnut gall wasp in the mid-2000s $[25,26]$. However, after studying the dead D. kuriphilus galls, Magro, et al. [27] reported that the galls and the associated leaves had in fact been killed by $G$. castaneae before the adults flew in. Upon this basis, the question arises as to whether $G$. castaneae could serve as a natural agent for the control of the chestnut gall wasp and other insect pests [28]. Apart from its profound phytopathogenic behavior, field observations and lab bioassays have demonstrated the possibility for G. castaneae to act also as an entomopathogenic fungus against chestnut pests, such as the chestnut gall wasp [27-31].

For this study, we recorded the survival of three major pests, the Indian Meal Moth Plodia interpunctella Hübner (Lepidoptera, Pyralidae), the Khapra beetle Trogoderma granarium Everts (Coleoptera, Dermestidae), and the Green Peach Aphid Myzus Persicae Sulzer (Hemiptera, Aphididae). The present study was designed to investigate the potential of G. castaneae as a biocontrol agent in comparison to a common EPF species, I. fumosorosea.

\section{Materials and Methods}

\subsection{Insects}

In order to evaluate the potential insecticidal action of G. castaneae on many different targets, three very diverse insect species (one beetle, one moth, and one aphid) were selected for experimentation. T. granarium was kept on whole wheat (var. Mexa), and only adults of mixed sex (younger than two weeks old) were used for experimental purposes. Uninfested grains were infested with adults; after one week, the adults were taken away, and the infested grains were kept in ambient conditions to obtain individuals of standardized age.

M. persicae was obtained from the Plant Protection Institute of Patras, ELGO Dimitra and was maintained on the potted pepper plant variety Stavros Peloponnesus (Capsicum annuum L., Solanales: Solanaceae). We pre-germinated the pepper plants in $2 \times 2 \mathrm{~cm}$ pots, sowing only one seed per pot at $1 \mathrm{~cm}$ in depth with Pindstrum plus peat substrate;we then transplanted them into $1 \mathrm{~L}$ pots with Pindstrum plus type peat substrate. Insects developed in a growth chamber (PHC Europe/Sanyo/Panasonic Biomedical MLR-352-PE), in stable conditions $\left(27 \pm 1{ }^{\circ} \mathrm{C}, 65 \pm 5 \% \mathrm{RH}\right.$, complete darkness). Throughout their developmental cycle, insects were in a room with pepper plants, at $25 \pm 1{ }^{\circ} \mathrm{C}, 60-70 \% \mathrm{RH}$, and photoperiod $16 / 8 \mathrm{~h}(\mathrm{~L} / \mathrm{N})$ constantly. 
Finally, the rearing of $P$. interpunctella took place in $25 \times 45 \times 30 \mathrm{~cm}$ cages. The frame of the cages, their sides, their back, and their floor were made of medium-density fiberboard (MDF); two sides were covered with a plastic mesh, and the front of the cage, which served as an entrance to the interior, was covered with a small cross-section plastic mesh. To each cage corresponded 15 to 20 pairs of adult insects. Sugar water was offered to adults with $1 \mathrm{~cm}$ cotton slices, placed in a Petri dish with water, on the floor of the cage. In the cages with $P$. interpunctella, we placed transparent plastic cassettes containing $200 \mathrm{~g}$ of whole flour, $100 \mathrm{~g}$ of bran, $80 \mathrm{~g}$ of brewing yeast, $130 \mathrm{~mL}$ of pure honey, and $100 \mathrm{~mL}$ of glycerol as artificial spawning substrate. The cassettes remained in the cages for two days and were then transferred to a dark place until the insects completed their biological cycle. We initially covered the cassettes with tulle to prevent the new larvae from escaping. The larvae were age-distributed in transparent containers to ensure their smooth development and equal food intake. The remaining food was stored at $4{ }^{\circ} \mathrm{C}$ until reused. Throughout their development, the insects remained in a room in stable conditions, at a temperature of $25 \pm 1{ }^{\circ} \mathrm{C}$, humidity of $60-70 \%$, and photoperiod $16 / 8 \mathrm{~h}$ light/dark.

\subsection{Fungal Isolates}

G. castaneae was isolated for the first time in 2015, from symptomatic chestnuts collected from European sweet chestnut orchards in Greece [32]. A single-spore isolate of G. castaneae belonging in the fungal collection of the Forest Research Institute was used.

I. fumosorosea (strain name: Ir Achaia) was a local strain from the Achaia region in Southern Greece. We kept the dishes at a temperature of $25 \pm 2{ }^{\circ} \mathrm{C}$ in the dark to ensure that the fungi incubated and developed properly. We isolated the developed fungi once again to ensure a clear cultivation. The conidia were collected from cultures which had grown on SDA dextrose agar (Sabouraud Dextrose Agar, OXOID LTD). We kept the isolates at $25 \pm 1{ }^{\circ} \mathrm{C}$, in Petri dishes containing a nutrient SDA material and we renewed them monthly. After 15 days, we collected fresh conidia from the SDA cultures to transfer them to a $500 \mathrm{~mL}$ glass beaker containing $100 \mathrm{~mL}$ of sterile distilled water with $0.05 \%$ Tergitol NP9. We filtered the conidial suspension through 10-12 layers of sterile cloth to separate hyphal debris and then mixed it with a magnetic stirrer for $5 \mathrm{~min}$. By means of a stereomicroscope, we examined bark samples for the teleomorphic stage of the fungus.

The viability of all test fungi was determined by spreading a $100 \mu \mathrm{L}$ aliquot of a conidia suspension $\left(1 \times 10^{6}\right.$ conidia $\left.\mathrm{mL}^{-1}\right)$, prepared with a sterile surfactant solution $(0.1 \% v / v)$ of Tween 80 , on SDA medium in Petri dishes $(90 \times 15 \mathrm{~mm})$ and incubated in the dark at $25 \pm 1{ }^{\circ} \mathrm{C}$. Plates of Isaria and Gnomoniopsis were incubated for 16 and $18 \mathrm{~h}$, respectively, prior to evaluation. Conidia were scored as viable if any germ tube was $2 \times$ longer than the diameter of the spore; a total of 100 conidia per sample were examined under $400 \times$ magnification.

Conidial viability was calculated based on the formula below:

Viability $(\%)=[\mathrm{G} 1 /(\mathrm{G} 1+\mathrm{G} 2)] \times 100$, where G1 refers to the number of germinated conidia, G2 is the number of non-germinated conidia, while the sum of G1 and G2 is equal to 100 . Thus, the viable conidia percentage was determined by counting a total of 100 conidia per fungal sample. Fungal strains presenting $\geq 90 \%$ viability was used in insect bioassays.

\subsection{Bioassays}

\subsubsection{Virulence Bioassay for T. granarium and P. interpuctella Larvae}

For T. granarium and P. interpuctella, we used $500 \mathrm{~g}$ of wheat which we placed in $0.45 \mathrm{~L}$ round glass jars. Two milliliters of conidial suspension were applied on the wheat at rates of $1 \times 10^{3}, 1 \times 10^{4}, 1 \times 10^{5}, 1 \times 10^{6}, 1 \times 10^{7}$, and $1 \times 10^{8}$ conidia per ml, using a Potter spray tower (Burkard Manufacturing Co. Ltd., Rickmansworth, Hertfordshire, UK) at $1 \mathrm{kgf} \mathrm{cm}^{-2}$. We adjusted the suspensions following Gurulingappa, et al. [33], using

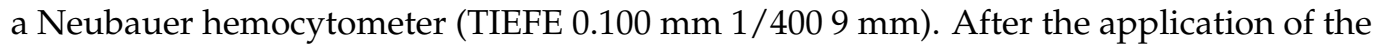
fungi, we returned the wheat lots to the jars and shook them manually for $30 \mathrm{~s}$ to ensure 
that the fungi would be equally distributed to the contents. The controls consisted of separate series of lots which were sprayed with distilled water plus $0.05 \%$ Tergitol NP9. From each jar, we took three $20 \mathrm{~g}$ samples and placed them in cylindrical plastic vials which were $3 \mathrm{~cm}$ in diameter and $8 \mathrm{~cm}$ in height. The lid of the vials was open in the center, which was covered with a fine mesh; the interior of the "neck" of the vials was covered with Fluon (Northern Products, Woonsocket, RI, USA) to prevent the escape of individuals. Ten T. granarium and $P$. interpunctella fourth-instar larvae were allocated per each vial (we used separate vials for each species). We placed the vials in plastic boxes containing saturated solutions of sodium chloride to stabilize the relative humidity at $75 \%$. The plastic boxes were finally placed in incubators set at $27.5^{\circ} \mathrm{C}$ and $75 \%$ R.H. We checked mortality daily for a period of 7 days. Larvae treated with I. fumosorosea were used as positive control in this study.

\subsubsection{Virulence Bioassay for M. persicae}

In the case of M. persicae, we rinsed the leaves of the pepper plants with tap water for $15 \mathrm{~min}$, we then washed them three times with distilled water, and we finally airdried them in a sterile laminar-flow hood. Working in the sterile hood, the leaves of the pepper were placed on $1.5 \%$ agar in plastic $90 \mathrm{~mm}^{2}$ petri dishes. The $1.5 \%$ agar was nutrient-free, but it supplied leaves with water so as to maintain $100 \%$ of relative humidity throughout the experiment. In the presence of aphids, the leaves sustained a satisfactory condition for at least 7 days. We sprayed the experimental leaves with the desired conidial suspension using a Potter spray tower (Burkard Manufacturing Co. Ltd., Rickmansworth, Hertfordshire, UK) at $1 \mathrm{kgf} \mathrm{cm}^{-2}$. We transferred the treated petri dishes into lid-covered plastic boxes. We applied $2 \mathrm{ml}$ of conidial suspension at rates of $1 \times 10^{3}, 1 \times 10^{4}, 1 \times 10^{5}$ $1 \times 10^{6}, 1 \times 10^{7}$, and $1 \times 10^{8}$ conidia per ml. Suspensions were adjusted as described. We determined the viability of conidia after $24 \mathrm{~h}$, by performing a repeat germination test for each stock suspension following Goettel and Inglis [34]; this was done to secure the constancy of the viability assessments. In all cases, the viability of conidia was on average exceeding $95 \%$. The controls consisted of separate series of lots which were sprayed with distilled water plus $0.05 \%$ Tergitol NP9. We placed 10 3-day-old aphid adults on each leaf, settled for $30 \mathrm{~min}$ after conidial treatment. We checked mortality daily for 7 days. I. fumosorosea was used as the positive control.

\subsection{Quantification of Conidial Production on Insect Cadavers}

After incubating the dead individuals in a humid chamber, five dead individuals covered with conidia (sporulated cadavers) were randomly removed from each sample of fungal treatment, surface-sterilized with sodium hypochlorite $(1 \% v / v)$ for $30 \mathrm{~s}$, rinsed twice in sterile distilled water for $30 \mathrm{~s}$, and then the cadavers were placed in a humid chamber maintained at $26{ }^{\circ} \mathrm{C}$ with $14 \mathrm{~h}$ photophase for 14 days. Cadavers bearing conspicuous masses of aerial conidia were placed individually in $1.5 \mathrm{~mL}$ Eppendorf tubes with $1 \mathrm{~mL}$ of a sterile solution of $0.1 \%$ Tween- 80 and vigorously vortexed for $1 \mathrm{~min}$ to dislodge the conidia from the insects' body. Subsequently, these same tubes were vortexed vigorously for $1 \mathrm{~min}$ and left in an ultrasonic bath for 2 min to enhance the suspension of conidia. Conidial density was calculated by hemocytometer counts at $40 \times$ magnification to determine the average of conidial production per insect. Three insect species and two repeated assays were used for each fungal strain, totaling 10 cadavers per treatment. Altogether, the conidial production was measured in 60 cadavers $(2$ treatments $\times 2$ experimental replicates $\times 5$ cadavers $\times 3$ insect species).

\subsection{Data Analysis}

We arcsine-transformed the mortality values to stabilize variance. Using the general linear model of the SPSS (SPSS Inc., IL, New York, USA, ver. 25), we then analyzed the data with univariate ANOVA for a multi-factor analysis. Where significant $F$ values occurred, we compared the means with the Bonferroni test. We calculated LC50 values by Probit 
analysis with 95\% confidence interval (CI) of the SPSS (SPSS Inc., IL, USA, ver. 25). The mean survival time of larvae and adults was determined with the Kaplan-Meier method.

\section{Results}

\subsection{Virulence of the Tested Fungi on Larvae of P. interpunctella}

Significant differences in larval mortality were detected among treatments $(\mathrm{F}=30.784$, $\mathrm{df}=1.1832, p<0.001)$, exposure time $(\mathrm{F}=7.022, \mathrm{df}=6.1832, p<0.001)$, and used EF concentrations $(\mathrm{F}=23.536, \mathrm{df}=6.1832, p<0.001)$. The main effects and interactions for all factors proved to be significant (Treatment * Exposure time: $\mathrm{F}=4.123, \mathrm{df}=6, p<0.001$; Treatment ${ }^{*}$ Concentration: $\mathrm{F}=2.570, \mathrm{df}=5, p=0.028$; Exposure time ${ }^{*}$ Concentration: $\mathrm{F}=8.464, \mathrm{df}=30, p<0.001$; Treatment $*$ Exposure time * Concentration: $\mathrm{F}=3.660, \mathrm{df}=30$, $p<0.001)$.

The mortality percentage depended on the dose of the used fungi. Final mortality percentages ( 7 days after exposure) of P. interpunctella larvae ranged from 10 to $86.5 \%$ with I. fumosorosea and from 6.7 to $50 \%$ with G. castaneae. Control treatment (using only $\mathrm{ddH}_{2} \mathrm{O}$ ) demonstrated minor mortality (3.3\%) at the end of the experiment (Figure 1 ). The survival time of $P$. interpunctella larvae treated with I. fumosorosea and G. castaneae was significantly reduced in comparison to the survival time of the control treatment. More specifically, after exposure to I. fumosorosea, the survival time of the larvae ranged from 6.56 to 4.6 days, and after exposure to G. castaneae, from 6.73 to 5.96 days. For control larvae, the survival time was 6.9 days (F: 3.667; df: 12; $p=0.030$ ).

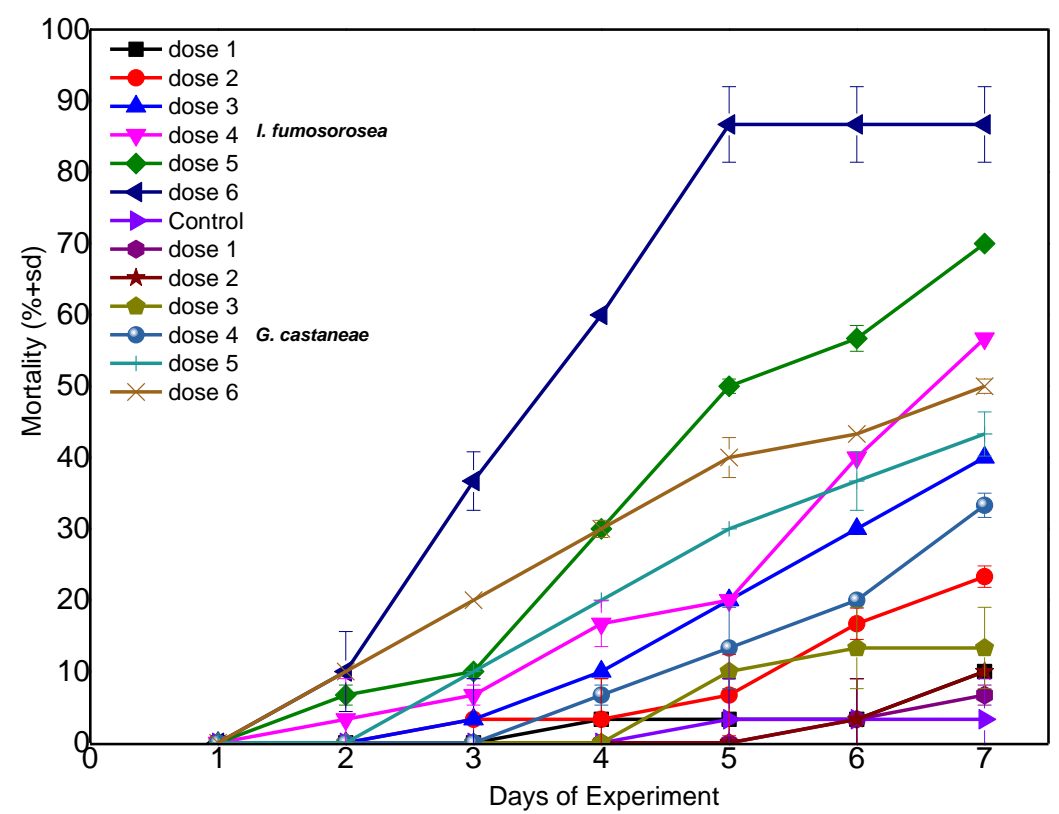

Figure 1. Average $(\% \pm \mathrm{sd})$ larval mortality of $P$. interpunctella treated with conidial suspensions of $I$. fumosorosea and G. castaneae at six concentrations $\left(1: 10^{3}, 2: 10^{4}, 3: 10^{5}, 4: 10^{6}, 5: 10^{7}, 6: 10^{8}\right)$.

\subsection{Virulence of the Tested Fungi on Larvae of T. granarium}

The final mortality ( 7 days after exposure) percentages of $T$. granarium larvae ranged from 10 to $73.3 \%$ with I. fumosorosea and from 3.3 to $36.7 \%$ with G. castaneae (Figure 2). Control treatment mortality amounted to $3.9 \%$ at the end of the experiment. The mortality percentage depended on the concentration of the used fungi. The survival time of T. granarium larvae treated with I. fumosorosea and G. castaneae was statistically significantly different in comparison to the survival time of control larvae. More specifically, after exposure to I. fumosorosea, the survival time of the larvae was 6.66-4.63 days, after exposure to G. castanea, it was 6.82-6.23 days, while after the control treatment, it was 6.9 days (F: 5.902; df: $12 ; p=0.015)$. 


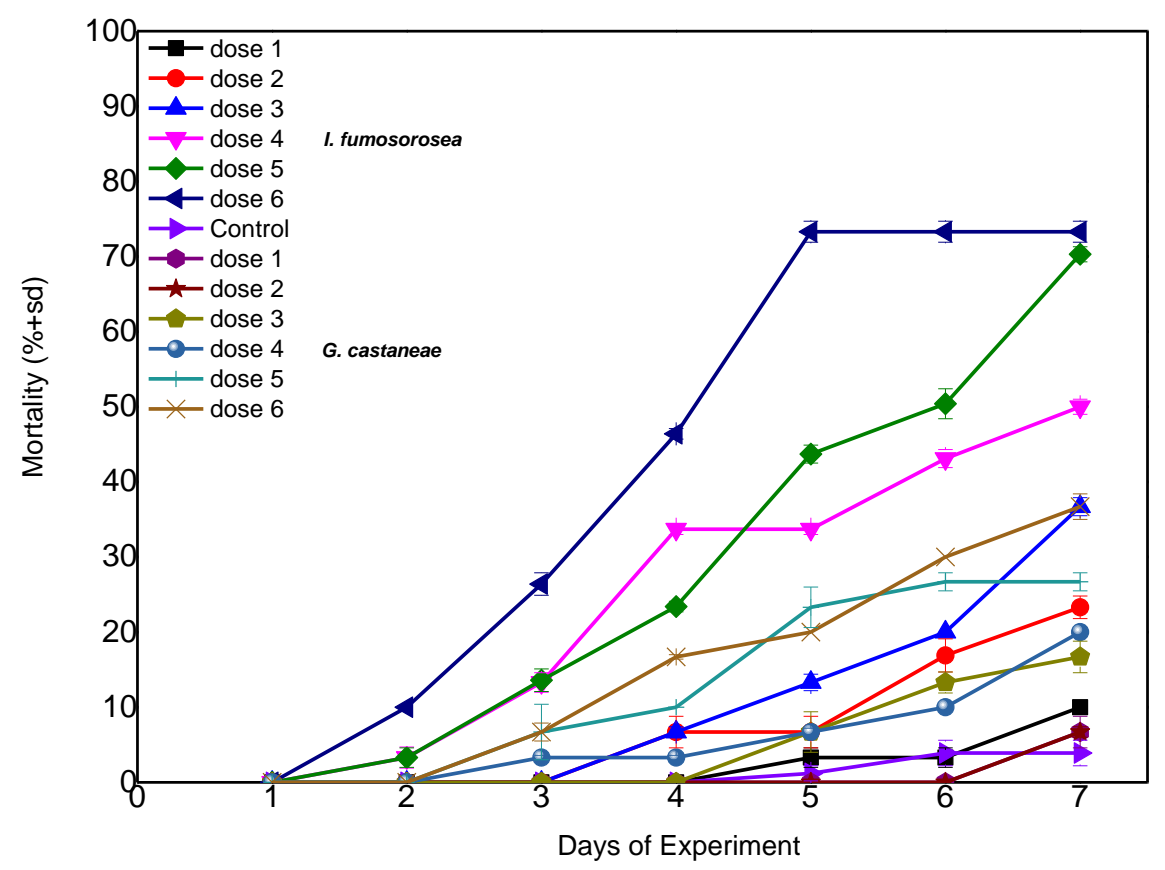

Figure 2. Average $(\% \pm \mathrm{sd})$ larval mortality of $T$. granarium treated with conidial suspensions of I. fumosorosea and G. castaneae at six concentrations $\left(1: 10^{3}, 2: 10^{4}, 3: 10^{5}, 4: 10^{6}, 5: 10^{7}, 6: 10^{8}\right)$.

Significant differences in the mortality of $T$. granarium larvae were detected among Treatments $(\mathrm{F}=55.706, \mathrm{df}=1.1832, p<0.001)$, Exposure time $(\mathrm{F}=4.503, \mathrm{df}=6.1832$, $p<0.001)$, and used Concentrations $(\mathrm{F}=21.546, \mathrm{df}=6.1832, p<0.001)$. The main effects and interactions for all factors proved to be significant (Treatment * Exposure time: $\mathrm{F}=7.164$, $\mathrm{df}=6, p<0.001$; Treatment ${ }^{*}$ Concentration: $\mathrm{F}=3.748, \mathrm{df}=5, p=0.003$; Exposure time * Concentration: $\mathrm{F}=5.195, \mathrm{df}=30, p<0.001$; Treatment ${ }^{*}$ Exposure time ${ }^{*}$ Concentration: $\mathrm{F}=7.804, \mathrm{df}=30, p<0.001$.

\subsection{Virulence of the Tested Fungi in Adults of M. persicae}

Significant differences in M. persicae adult's mortality were detected among Treatments $(\mathrm{F}=71.062, \mathrm{df}=1.1832, p<0.001)$, Exposure time $(\mathrm{F}=6.347, \mathrm{df}=6.1832, p<0.001)$, and used Concentrations $(\mathrm{F}=18.105, \mathrm{df}=6.1832, p<0.001)$. The main effects and interactions for all factors proved to be significant (Treatment * Exposure time: $\mathrm{F}=7.994, \mathrm{df}=6, p<0.001$; Treatment ${ }^{*}$ Concentration: $\mathrm{F}=4.430, \mathrm{df}=5, p<0.001$; Exposure time ${ }^{*}$ Concentration: $\mathrm{F}=4.668, \mathrm{df}=30, p<0.001$; Treatment ${ }^{*}$ Exposure time * Concentration: $\mathrm{F}=4.317, \mathrm{df}=30$, $p<0.001$ ).

On day 7 after exposure, the final mortality percentages of $M$. persicae adults were 26.7 to $86.7 \%$ with I. fumosorosea and 6.7 to $36.7 \%$ with G. castaneae (Figure 3). For the control, larvae mortality was $6.7 \%$ at the end of the experiment. The mortality percentage was dose dependent. The survival time of $M$. persicae adults treated with I. fumosorosea and G. castaneae was statistically significant in comparison to the survival time of control adults. More specifically, the survival time of adults was 6.43-4.46 days after exposure to I. fumosorosea and 6.56-5.96 days after exposure to G. castaneae. For control adults, the survival time was 6.76 days (F: 6.117; df: $12 ; p=0.017$ ). 


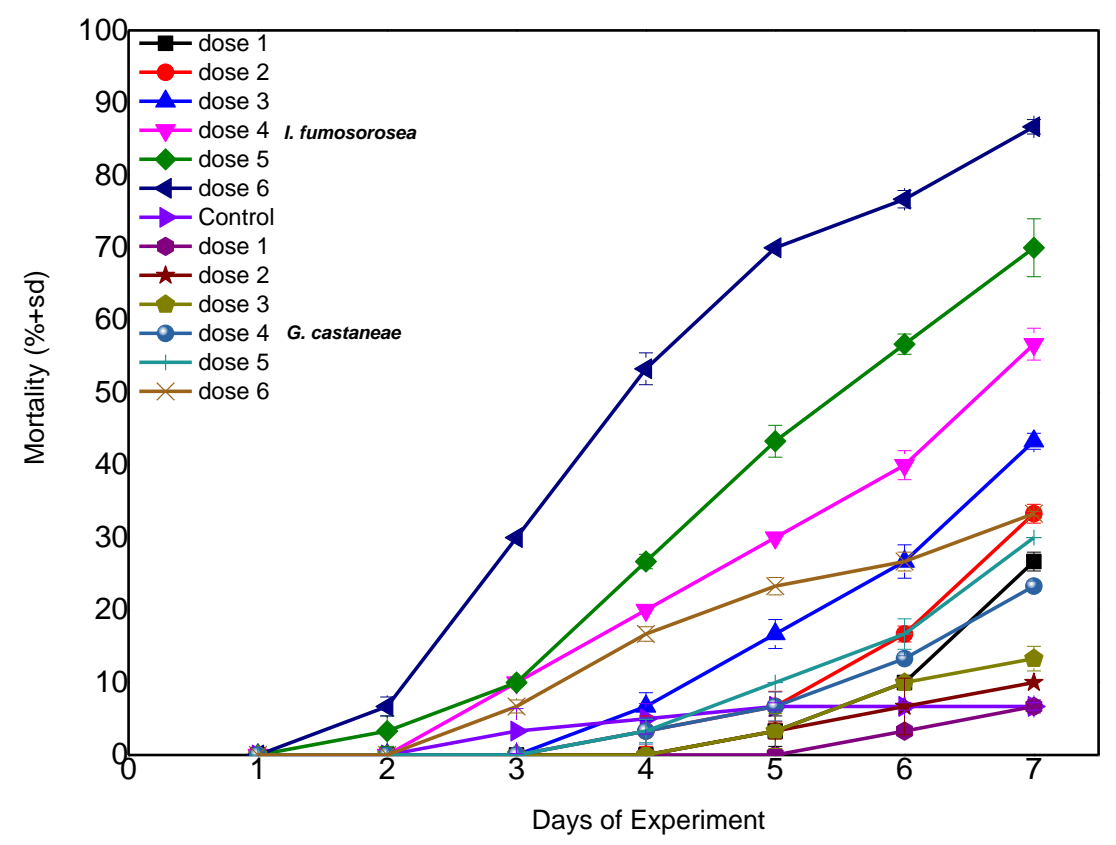

Figure 3. Average $(\% \pm \mathrm{sd})$ adult mortality of $M$. persicae treated with conidial suspensions of I. fumosorosea and G. castaneae at six concentrations $\left(1: 10^{3}, 2: 10^{4}, 3: 10^{5}, 4: 10^{6}, 5: 10^{7}, 6: 10^{8}\right)$.

\subsection{Lethal Concentration of the Fungi}

Probit analysis results showed that the median lethal concentrations (LC50) of I. fumosorosea after a 7-day exposure were: $8.3 \times 10^{4}$ conidia $/ \mathrm{mL}$ (for P. interpunctella), $3.1 \times 10^{5}$ conidia $/ \mathrm{mL}$ (for T. granarium), and $6.5 \times 10^{4}$ conidia $/ \mathrm{mL}$ (for M. persicae). The respective estimated values for G. castaneae were: $9.3 \times 10^{6}$ conidia $/ \mathrm{mL}$ (for P. interpunctella), $1.5 \times 10^{9}$ conidia $/ \mathrm{mL}$ (for T. granarium), and $1.8 \times 10^{8}$ conidia $/ \mathrm{mL}$ (for M. persicae). Significant differences in LC50 values were recorded between the two different entomopathogenic fungi in all cases (Table 1).

Table 1. Pathogenicity of I. fumosorosea and G. castaneae against P. interpunctella, T. granarium, and M. persicae. The value of each $\chi^{2}$ refers to the probability of the angular coefficient $>0$. LC-values and slopes (in $g / L$ ) were estimated by the probit procedure.

\begin{tabular}{|c|c|c|c|c|c|c|}
\hline Treatment & Insect & Slope & Intercept & $\mathbf{R}^{2}$ & $\begin{array}{c}\text { LC50 }(95 \% \text { CI }) \\
\text { Conidia/mL }\end{array}$ & $\begin{array}{c}\text { Chi-Test }\left(\chi^{2}\right) \\
\text { Sig }\end{array}$ \\
\hline I. fumosorosea & \multirow[t]{2}{*}{ P. interpunctella } & 0.472 & 2.205 & 0.991 & $\begin{array}{c}8.3 \times 10^{4} \\
\left(14.7 \times 10^{3}-4.6 \times 10^{5}\right)\end{array}$ & 0.994 \\
\hline G. castaneae & & 0.448 & 1.431 & 0.951 & $\begin{array}{c}9.3 \times 10^{6} \\
\left(1.1 \times 10^{5}-7.6 \times 10^{7}\right)\end{array}$ & 0.653 \\
\hline I. fumosorosea & \multirow[t]{2}{*}{ T. granarium } & 0.366 & 2.625 & 0.982 & $\begin{array}{c}3.1 \times 10^{5} \\
\left(3.5 \times 10^{4}-2.7 \times 10^{6}\right.\end{array}$ & 0.998 \\
\hline G. castaneae & & 0.254 & 2.412 & 0.934 & $\begin{array}{c}1.5 \times 10^{9} \\
\left(3.6 \times 10^{8}-6.8 \times 10^{10}\right)\end{array}$ & 0.063 \\
\hline I. fumosorosea & \multirow[t]{2}{*}{ M. persicae } & 0.331 & 3.073 & 0.983 & $\begin{array}{c}6.5 \times 10^{4} \\
\left(6.3 \times 10^{3}-6.6 \times 10^{5}\right)\end{array}$ & 0.997 \\
\hline G. castaneae & & 0.339 & 1.858 & 0.959 & $\begin{array}{c}1.8 \times 10^{8} \\
\left(9.9 \times 10^{6}-3.4 \times 10^{10}\right)\end{array}$ & 0.845 \\
\hline
\end{tabular}

\subsection{Conidial Production by Sporulated Cadavers}

Conidial production on the infected cadavers varied strongly among fungal strains $(\mathrm{F}=3902, \mathrm{df}=10, p<0.0001)$, with the Isaria strain producing higher numbers of conidia per cadaver for all tested species $\left(6.5 \times 10^{8}\right.$ conidia per T. granarium, $3.8 \times 10^{8}$ conidia per 
P. interpuctella, $2.1 \times 10^{8}$ conidia per $M$. persicae). On the other hand, relevant G. castaneae post-mortem conidial production was $1.5 \times 10^{4}$ conidia per $T$. granarium, $2.3 \times 10^{4}$ conidia per $M$. persicae cadavers, and $1 \times 10^{5}$ conidia per $P$. interpuctella cadaver.

\section{Discussion}

Although EPFs are already available for commercial use [35-40], basic and applied research is still necessary to improve their virulence and enhance their role in Integrated Pest Management (IPM). Although the original habitat underlines the pathogenicity of EPF species [41], evaluation assays of potential isolates should not be targeted only at the original host, but also at various insect pests, as it was clearly indicated by our results.

We used two major stored product pests for experimentation, because there is a plethora of publications on the effect of EPF species against insect pests of stored products, often with contradictory results [2,37,40,42-50]. Demirci, et al. [51] stated that the entomopathogen Isaria farinosa achieved high pathogenic activity on the citrus mealybug, especially under humid conditions, and caused high mortality within six days of incubation. Also, Cherry, et al. [46] showed that different isolates of M. anisopliae and B. bassiana can achieve a satisfactory control of Callosobruchus maculatus (F.) (Coleoptera: Bruchidae) by immersion bioassay at $12 \mathrm{~d}$, whereby $B$. bassiana proved more virulent than $M$. anisopliae. Khashaveh, et al. [47] claimed B. bassiana to be successful against stored wheat pests. In a similar vein, Wakefield, et al. [48] and Storm, et al. [49] reported that some B. bassiana isolates can achieve $100 \%$ mortality of the organophosphate resistant strain of Oryzaephilus surinamensis (L.) (Coleoptera: Silvanidae) after $10 \mathrm{~d}$ of treatment at $1 \times 10^{8}$ conidia $/ \mathrm{mL}$. In older studies, the mortality of stored grain pests reached $80-100 \%$ after $10-20 \mathrm{t}$ the ina same doses [2,50]. Ekesi, et al. [52] showed that the efficacy of M. anisopliae and B. bassiana, was over $90 \%$ on treated larvae of the African tephritid fruit fly.

We used I. fumosorosea as a positive control given that it has demonstrated noteworthy virulence (70-100\%) in numerous studies against many insect pests [53-55] and has often exhibited the highest pathogenicity in comparison with other EPF species [56]. The current study mainly focused on the entomopathogenic potential of G. castaneae in comparison with that of I. fumosorosea. Although Gnomoniopsis castaneae proved to be entomopathogenic, it caused low pathogenicity to $M$. persicae and T. granarium, but significant mortality levels, especially at the highest conidial concentration, to P. interpunctella. On the other hand, the I. fumosorosea native strain caused a mortality of $86.7 \%$ to P. interpunctella, $86.7 \%$ to M. persicae, and $73.3 \%$ to $T$. granarium at high conidial doses. On the other hand, Michalaki, et al. [57] found that I. fumosorosea was not effective against adults and larvae of Tribolium confusum (Coleoptera: Tenebrionidae) Jacquelin du Val and of Ephestia kuehniella Zeller (Lepidoptera: Pyralidae).

The dependency of a fungal disease on conidial concentration normally indicates that a higher conidial density will often result in a faster control of the targeted insects. Consequently, where large insect pest populations exist, higher conidial concentrations are more effective to contain pest populations from incurring economic damages. However, low conidial concentrations can also be used in the initial developmental stages of pest populations to maintain them below economically damaging thresholds. Tuncer, et al. [58] and Kushiyev, et al. [8] showed that the LT50 and LT90 values of M. anisopliae and B. bassiana isolates applied to females of the European gypsy moth and of the Black timber bark beetle decreased by increasing conidial concentrations. Shams, et al. [59] used probit analysis to estimate the LT50 of B. bassiana at 10.45 days against C. maculatus and Sitophilus granarius (L.) (Coleoptera: Curculionidae). In our experiment, the survival time of larvae of P. interpunctella and T. granarium and of adults of $M$. persicae depended on the dose of the fungi. In the case of G. castaneae, the survival time of the tested insects was very high in relation to the survival time of I. fumosorosea in the same insects and at the same doses. This indicates that G. castaneae did not generate a high enough entomopathogenic impact on the tested insects. 
The quality of nutrients in host cadavers may also be an important factor for in-spore production. This depends greatly on the enzymatic machinery of the fungus to utilize all components of the dead host. It has been postulated that a fungus producing large numbers of infective propagules could enhance fungal population density in host environments and the likelihood of conidial transmission or spread in the host population. However, we found a relationship between virulence and conidial production on cadavers, which means that highly lethal EPF strains such I. fumosorosea are necessarily prolific in producing offspring from cadavers, as they require shorter time and smaller inoculum doses to kill insects than low-virulence EPF strains like G. castaneae. In agreement with our results, the relationship between virulence and conidial production has been also verified for EPF strains infesting the Mediterranean corn borer Sesamia nonagrioides Lefèbvre (Lepidoptera: Noctuidae) [60].

The insecticidal efficacy of EPF depends on many other factors such as the behavior of the insect, its age, its population density, nutrition, genetics, as well the degree of host physiology and morphology tolerance to biological control agents [61]. In this sense, variation in insect susceptibility to EPF could not be accounted for only in terms of the applied conidial concentration [62]. Frankliniella occidentalis Pergande (Thysanoptera: Thripidae), which had been exposed to B. bassiana, was marked by reduced reproductive ability of its progeny [63]; Aedes aegypti L. (Diptera: Culicidae) larvae, which had survived infection from the fungal pathogen Leptolegnia chapmanii Seymoor (Peronosporomycetes: Saprolegniales), had their reproduction disrupted, thus laying fewer eggs [64]. Greater wax moth larvae developed only low resistance to $B$. bassiana even after 25 generations of selection [65].

The entomopathogenic action of $G$. castaneae is not a surprise, as it has been considered the principal mortality factor for the oriental chestnut gall wasp and, especially, the main factor for the inability of adult wasps to emerge [66]. This insecticidal action of G. castaneae has been associated with various causes such as spore production, host population, and ecological factors $[28,66]$.

\section{Conclusions}

In the current study, G. castaneae failed to cause high pathogenicity against larvae of $P$. interpunctella and T. granarium and adults of $M$. persicae. Drawing on these results, G. castaneae may not be the ideal EPF candidate to select for a biological control strategy. However, it should be taken under consideration that virulence is not the only desired characteristic of an effective biocontrol agent. Compatibility with other IPM methods (physical control, cultural measures, etc.), cost of mass production, difficulty in handling, ease of application, performance in challenging environments, shelf-life, formulation issues, and many other parameters should also be tested when evaluating a biocontrol agent. Apart from that, our study reiterates the pathogenic potential of I. fumosorosea against larvae of P. interpunctella and T. granarium and adults of M. persicae and indicates that it can be used as a biocontrol agent. Although this represents only a preliminary investigative stage into the use of G. castaneae, our study does not render promising results, but reinforces our knowledge of the insecticidal value of I. fumosorosea. More studies are needed to further our insight into the potential of G. castaneae species as a component of IPM.

Author Contributions: Conceptualization, S.M. and D.N.A.; methodology, S.M.; software, S.M.; validation, S.M., P.A.E., D.N.A., and K.P.; formal analysis, S.M., I.L., and A.N.; investigation, S.M., I.L., and A.N.; resources, S.M. and D.N.A.; data curation, S.M.; writing-original draft preparation, S.M., A.N., D.N.A., P.A.E., and K.P.; writing-review and editing, S.M., G.T.T., P.A.E., D.N.A., and K.P.; visualization, S.M.; supervision, S.M. and D.N.A.; project administration, S.M. and D.N.A. All authors have read and agreed to the published version of the manuscript.

Funding: This research received no external funding.

Institutional Review Board Statement: Not applicable.

Informed Consent Statement: Not applicable. 


\section{Data Availability Statement: Not applicable.}

Acknowledgments: We would like to thank Ioanna Zampara, MA in interpreting and translating, for her help with the English language.

Conflicts of Interest: The authors declare no conflict of interest.

\section{References}

1. Roy, H.; Steinkraus, D.; Eilenberg, J.; Hajek, A.; Pell, J. Bizarre Interactions and Endgames: Entomopathogenic Fungi and their Arthropod Hosts. Annu. Rev. Èntomol. 2006, 51, 331-357. [CrossRef]

2. Rice, W.C.; Cogburn, R.R. Activity of the Entomopathogenic Fungus Beauveria bassiana (Deuteromycota: Hyphomycetes) Against Three Coleopteran Pests of Stored Grain. J. Econ. Èntomol. 1999, 92, 691-694. [CrossRef]

3. Shahid, A.; Rao, Q.; Bakhsh, A.; Husnain, T. Entomopathogenic Fungi as Biological Controllers: New Insights into their Virulence and Pathogenicity. Arch. Biol. Sci. 2012, 64, 21-42. [CrossRef]

4. Sierotzki, H.; Wullschleger, J.; Gisi, U. Point Mutation in Cytochrome b Gene Conferring Resistance to Strobilurin Fungicides in Erysiphe Graminis f. sp. Tritici Field Isolates. Pestic. Biochem. Physiol. 2000, 68, 107-112. [CrossRef]

5. Shaw, E.K.; Davidson, G.; Clark, S.J.; Ball, B.V.; Pell, J.K.; Chandler, D.; Sunderland, K.D. Laboratory Bioassays to Assess the Pathogenicity of Mitosporic Fungi to Varroa Destructor (Acari: Mesostigmata), an Ectoparasitic Mite of the Honeybee, Apis Mellifera. Biol. Control 2002, 24, 266-276. [CrossRef]

6. Sani, I.; Ismail, S.I.; Abdullah, S.; Jalinas, J.; Jamian, S.; Saad, N. A Review of the Biology and Control of Whitefly, Bemisia tabaci (Hemiptera: Aleyrodidae), with Special Reference to Biological Control Using Entomopathogenic Fungi. Insects 2020, 11, 619. [CrossRef]

7. Gao, T.; Wang, Z.; Huang, Y.; Keyhani, N.O.; Huang, Z. Lack of Resistance Development in Bemisia Tabaci to Isaria fumosorosea after Multiple Generations of Selection. Sci. Rep. 2017, 7, 1-11. [CrossRef]

8. Kushiyev, R.; Tuncer, C.; Erper, I.; Ozdemir, I.O.; Saruhan, I. Efficacy of Native Entomopathogenic Fungus, Isaria fumosorosea, against Bark and Ambrosia Beetles, Anisandrus dispar Fabricius and Xylosandrus germanus Blandford (Coleoptera: Curculionidae: Scolytinae). Egypt. J. Biol. Pest Control 2018, 28, 55. [CrossRef]

9. Ali, B.G.; Cao, N.; Wang, B.; Hua, F.L. Control of Plant Sap-Sucking Insects using Entomopathogenic Fungi Isaria fumosorosea Strain (Ifu13a). Plant Prot. Sci. 2018, 54, 258-264. [CrossRef]

10. Hunter, W.B.; Avery, P.B.; Pick, D.; Powell, C.A. Broad Spectrum Potential of Isaria fumosorosea Against Insect Pests of Citrus. Fla. Èntomol. 2011, 94, 1051-1054. [CrossRef]

11. Li, H.U.; Yu, R.H.; Ya, J.W.; Xia, F.; Huan, Y.C. The Time-Dose-Mortality Model of a Paecilomyces fumosoroseus Isolate on the Diamondback Moth, Plutella xylostella. Acta Entomol. Sin. 2007, 50, 567-573.

12. Altre, J.; Vandenberg, J.; Cantone, F. Pathogenicity of Paecilomyces fumosoroseus Isolates to Diamondback Moth, Plutella xylostella: Correlation with Spore Size, Germination Speed, and Attachment to Cuticle. J. Invertebr. Pathol. 1999, 73, 332-338. [CrossRef] [PubMed]

13. Altre, J.; Vandenberg, J. Factors Influencing the Infectivity of Isolates of Paecilomyces fumosoroseus against Diamondback Moth, Plutella xylostella. J. Invertebr. Pathol. 2001, 78, 31-36. [CrossRef] [PubMed]

14. De Faria, M.R.; Wraight, S.P. Mycoinsecticides and Mycoacaricides: A Comprehensive list with Worldwide Coverage and International Classification of Formulation Types. Biol. Control 2007, 43, 237-256. [CrossRef]

15. Dennert, F.G.; Broggini, G.A.L.; Gessler, C.; Storari, M. Gnomoniopsis Castanea is the Main Agent of Chestnut Nut Rot in Switzerland. Phytopathol. Mediterr. 2015, 54, 199-211. [CrossRef]

16. Shuttleworth, L.A.; Walker, D.M.; Guest, D.I. The Chestnut Pathogen Gnomoniopsis smithogilvyi (Gnomoniaceae, Diaporthales) and its Synonyms. Mycotaxon 2016, 130, 929-940. [CrossRef]

17. Visentin, I.; Gentile, S.; Valentino, D.; Gonthier, P.; Tamietti, G.; Cardinale, F. Gnomoniopsis castanea sp. Nov. (Gnomoniaceae, Diaporthales) as the Causal Agent of Nut Rot in Sweet Chestnut. J. Plant Pathol. 2012, 94, 411-419.

18. Smith, H.C.; Ogilvy, D. Nut Rot in Chestnuts. Austr. Nutgrow 2008, 22, 11-15.

19. Maresi, G.; Longa, C.O.; Turchetti, T. Brown Rot on Nuts of Castanea Sativa Mill: An Emerging Disease and its Causal Agent. iForest Biogeosci. For. 2013, 6, 294-301. [CrossRef]

20. Pasche, S.; Calmin, G.; Auderset, G.; Crovadore, J.; Pelleteret, P.; Mauch-Mani, B.; Barja, F.; Paul, B.; Jermini, M.; Lefort, F. Gnomoniopsis Smithogilvyi causes Chestnut Canker Symptoms in Castanea Sativa Shoots in Switzerland. Fungal Genet. Biol. 2016, 87, 9-21. [CrossRef]

21. Dar, M. Gnomoniopsis smithogilvyi, a Canker causing Pathogen on Castanea Sativa: First Report. Mycosphere 2015, 6, 327-336. [CrossRef]

22. Lione, G.; Giordano, L.; Sillo, F.; Gonthier, P. Testing and Modelling the Effects of Climate on the Incidence of the Emergent Nut Rot Agent of Chestnut Gnomoniopsis castanea. Plant Pathol. 2015, 64, 852-863. [CrossRef]

23. Lione, G.; Danti, R.; Fernandez-Conradi, P.; Ferreira-Cardoso, J.V.; Lefort, F.; Marques, G.; Meyer, J.B.; Prospero, S.; Radócz, L.; Robin, C.; et al. The Emerging Pathogen of Chestnut Gnomoniopsis castaneae: The Challenge Posed by a Versatile Fungus. Eur. J. Plant Pathol. 2019, 153, 671-685. [CrossRef]

24. Ogilvy, D. Phomopsis When does it Strike? Aust. Nutgrow 1998, 12, 16-18. 
25. Martinez-Sañudo, I.; Mazzon, L.; Simonato, M.; Avtzis, D.; Pujade-Villar, J.; Faccoli, M. Tracking the Origin and Dispersal of the Asian Chestnut Gall Wasp Dryocosmus kuriphilus Yasumatsu (Hymenoptera, Cynipidae) in Europe with Molecular Markers. Bull. Èntomol. Res. 2018, 109, 300-308. [CrossRef] [PubMed]

26. Avtzis, D.N.; Melika, G.; Matošević, D.; Coyle, D.R. The Asian Chestnut Gall Wasp Dryocosmus kuriphilus: A Global Invader and a Successful Case of Classical Biological Control. Anz. Für Schädl. Pflanz. Und Umweltschutz 2018, 92, 107-115. [CrossRef]

27. Magro, P.; Speranza, S.; Stacchiotti, M.; Martignoni, D.; Paparatti, B. Gnomoniopsis Associated with Necrosis of Leaves and Chestnut Galls Induced by Dryocosmus kuriphilus. Plant Pathol. 2010, 59, 1171. [CrossRef]

28. Vannini, A.; Vettraino, A.; Martignoni, D.; Morales-Rodriguez, C.; Contarini, M.; Caccia, R.; Paparatti, B.; Speranza, S. Does Gnomoniopsis Castanea Contribute to the Natural Biological Control of Chestnut Gall Wasp? Fungal Biol. 2017, 121, 44-52. [CrossRef] [PubMed]

29. Vannini, A.; Morales-Rodriguez, C.; Aleandri, M.; Bruni, N.; Valle, M.D.; Mazzetto, T.; Martignoni, D.; Vettraino, A. Emerging New Crown Symptoms on Castanea sativa (Mill.): Attempting to Model Interactions among Pests and Fungal Pathogens. Fungal Biol. 2018, 122, 911-917. [CrossRef]

30. Lione, G.; Giordano, L.; Ferracini, C.; Alma, A.; Gonthier, P. Testing Ecological Interactions between Gnomoniopsis castaneae and Dryocosmus kuriphilus. Acta Oecol. 2016, 77, 10-17. [CrossRef]

31. Seddaiu, S.; Cerboneschi, A.; Sechi, C.; Mello, A. Gnomoniopsis castaneae Associated with Dryocosmus kuriphilus Galls in Chestnut Stands in Sardinia (Italy). iForest Biogeosci. For. 2017, 10, 440-445. [CrossRef]

32. Tziros, G.T. First Report of Nut Rot Caused by Gnomoniopsis castaneae on Castanea sativa in Greece. J. Plant Pathol. 2018, 101, 211. [CrossRef]

33. Gurulingappa, P.; Sword, G.A.; Murdoch, G.; McGee, P.A. Colonization of Crop Plants by Fungal Entomopathogens and their Effects on Two Insect Pests when in Planta. Biol. Control 2010, 55, 34-41. [CrossRef]

34. Goettel, M.S.; Douglas Inglis, G. Chapter V-3_Fungi: Hyphomycetes; Springer: Berlin, Germany, 1997 ; ISBN 9780124325555.

35. Miller, D.W. Commercial Development of Entomopathogenic Fungi. ACS Symp. Ser. 1995, 213-220. [CrossRef]

36. Maina, U.M.; Zakaria, D.; Galadima, I.B.; Gambo, F.M. A review on the Use of Entomopathogenic Fungi in the Management of Insect Pests of Field Crops. J. Entomol. Zool. Stud. 2018, 6, 27-32.

37. Kontodimas, D.C.; Kavallieratos, N.G.; Mantzoukas, S.; Athanassiou, C.G.; Anagnou-Veroniki, M. Effect of Beauveria bassiana, Verticillium lecanii, Bacillus thuringiensis Ssp. Tenebrionis and Azadiractin Compounds on Sitophilus oryzae (L.) and Tribolium confusum DUVAL in Stored Rye. In Proceedings of the Society for Invertebrate Pathology 37th Annual Meeting, Helsinki, Finland, 6 August 2004; pp. 94-95.

38. Mantzoukas, S.; Lagogiannis, I.; Mpekiri, M.; Pettas, I.; Eliopoulos, P.A. Insecticidal Action of Several Isolates of Entomopathogenic Fungi against the Granary Weevil Sitophilus granarius. Agriculture 2019, 9, 222. [CrossRef]

39. Mantzoukas, S.; Lagogiannis, I.; Pettas, I.; Korbou, G.; Magita, A.; Papadopoulou, A.; Trianti, M.; Eliopoulos, P.A.; Karanastasi, E. Postharvest Treatment of Tribolium confusum Jacquelin du Val Adults with Commercial Biopesticides. Agriculture 2019, 9, 226. [CrossRef]

40. Mantzoukas, S.; Lagogiannis, I.; Karmakolia, K.; Rodi, A.; Gazepi, M.; Eliopoulos, P.A. The Effect of Grain Type on Virulence of Entomopathogenic Fungi against Stored Product Pests. Appl. Sci. 2020, 10, 2970. [CrossRef]

41. Bidochka, M.J.; Kamp, A.M.; De Croos, J.N.A. Insect Pathogenic Fungi: From Genes to Populations. Fungal Pathol. 2000, 171-193. [CrossRef]

42. Hidalgo, E.; Moore, D.; Le Patourel, G. The Effect of Different Formulations of Beauveria bassiana on Sitophilus zeamais in Stored Maize. J. Stored Prod. Res. 1998, 34, 171-179. [CrossRef]

43. Batta, Y. Control of the Lesser Grain Borer (Rhyzopertha dominica (F.), Coleoptera: Bostrichidae) by Treatments with Residual Formulations of Metarhizium anisopliae (Metschnikoff) Sorokin (Deuteromycotina: Hyphomycetes). J. Stored Prod. Res. 2005, 41, 221-229. [CrossRef]

44. Bello, G.D.; Padín, S.; Juarez, P.; Pedrini, N.; De Giusto, M. Biocontrol of Acanthoscelides obtectus and Sitophilus oryzae with Diatomaceous Earth and Beauveria bassiana on Stored Grains. Biocontrol Sci. Technol. 2006, 16, 215-220. [CrossRef]

45. Moino, A.; Alves, S.B.; Pereira, R.M. Efficacy of Beauveria Bassiana(Balsamo) Vuillemin Isolates for Control of Stored-Grain pests. J. Appl. Èntomol. 1998, 122, 301-305. [CrossRef]

46. Cherry, A.; Abalo, P.; Hell, K. A Laboratory Assessment of the Potential of Different Strains of the Entomopathogenic Fungi Beauveria bassiana (Balsamo) Vuillemin and Metarhizium anisopliae (Metschnikoff) to Control Callosobruchus maculatus (F.) (Coleoptera: Bruchidae) in Stored Cowpea. J. Stored Prod. Res. 2005, 41, 295-309. [CrossRef]

47. Khashaveh, A.; Gusta, Y.; Safaralizadeh, M.H.; Ziaee, M. The Use of Entomopathogenic Fungus, Beauveria bassiana (Bals.) Vuill. in Assays with Storage Grain Beetles. J. Agric. Sci. Technol. 2011, 13, 35-43.

48. Wakefield, M.E.; Moore, D.; Luke, B.; Taylor, B.; Collins, D.A.; Storm, C.; Grammare, P.; Potin, O.; Young, R. Biopesticides for the Control of Storage Insect Pests. Available online: https:/ / orgprints.org/id/eprint/6769/ (accessed on 27 April 2021).

49. Storm, C.; Scoates, F.; Nunn, A.; Potin, O.; Dillon, A. Improving Efficacy of Beauveria bassiana against Stored Grain Beetles with a Synergistic Co-Formulant. Insects 2016, 7, 42. [CrossRef] [PubMed]

50. Padin, S.B.; Bello, G.M.; Vasicek, A.L. Pathogenicity of Beauveria Bassiana for adults of Tribolium Castaneum (Col.: Tenebrionidae) in Stored Grains. BioControl 1997, 42, 569-574. [CrossRef] 
51. Demirci, F.; Muştu, M.; Kaydan, M.B.; Ülgentürk, S. Laboratory Evaluation of the Effectiveness of the Entomopathogen; Isaria farinosa, on Citrus Mealybug, Planococcus Citri. J. Pest Sci. 2011, 84, 337-342. [CrossRef]

52. Ekesi, S.; Maniania, N.K.; Lux, S.A. Mortality in Three African Tephritid Fruit Fly Puparia and Adults Caused by the Entomopathogenic Fungi, Metarhizium anisopliae and Beauveria bassiana. Biocontrol Sci. Technol. 2002, 12, 7-17. [CrossRef]

53. Duarte, R.T.; Gonçalves, K.C.; Espinosa, D.J.L.; Moreira, L.F.; De Bortoli, S.A.; Humber, R.A.; Polanczyk, R.A. Potential of Entomopathogenic Fungi as Biological Control Agents of Diamondback Moth (Lepidoptera: Plutellidae) and Compatibility With Chemical Insecticides. J. Econ. Èntomol. 2016, 109, 594-601. [CrossRef]

54. Boopathi, T.; Karuppuchamy, P.; Singh, S.B.; Kalyanasundaram, M.; Mohankumar, S.; Ravi, M. Microbial Control of the Invasive Spiraling Whitefly on Cassava with Entomopathogenic Fungi. Braz. J. Microbiol. 2015, 46, 1077-1085. [CrossRef] [PubMed]

55. Robert, S.; Petra, C.; Juraj, M.; Marek, B. Natural Prevalence of Entomopathogenic Fungi in Hibernating Pupae of Cameraria ohridella (Lepidoptera: Gracillariidae) and Virulence of Selected Isolates. Plant Prot. Sci. 2016, 52, 199-208. [CrossRef]

56. Fiaz, M.; Afzal, M.; Majeed, M.Z. Synergistic Action of Isaria fumosorosea Wize (Hypocreales: Cordycipitaceae) and Spirotetramat against Asian Citrus Psyllid, Diaphorina citri Kuwayama (Hemiptera: Psyllidae) under Field Conditions. Pak. J. Agric. Res. 2018, 31, 211-216. [CrossRef]

57. Michalaki, M.; Athanassiou, C.; Steenberg, T.; Buchelos, C. Effect of Paecilomyces fumosoroseus (Wise) Brown and Smith (Ascomycota: Hypocreales) Alone or in Combination with Diatomaceous Earth against Tribolium confusum Jacquelin du Val (Coleoptera: Tenebrionidae) and Ephestia kuehniella Zeller (Lepidoptera: Pyralidae). Biol. Control 2007, 40, 280-286. [CrossRef]

58. Tuncer, C.; Kushiyev, R.; Erper, I.; Ozdemir, I.O.; Saruhan, I. Efficacy of Native Isolates of Metarhizium anisopliae and Beauveria bassiana against the Invasive Ambrosia Beetle, Xylosandrus germanus Blandford (Coleoptera: Curculionidae: Scolytinae). Egypt. J. Biol. Pest Control 2019, 29, 28. [CrossRef]

59. Golnaz, S.; Mohammad, H.S.; Sohrab, I.; Mahmoud, S.; Shahram, A.; Rajiah, K.; Mathew, E.M. A Laboratory Assessment of the Potential of the Entomopathogenic Fungi Beauveria bassiana (Beauvarin) to Control Callosobruchus maculatus (F.) (Coleoptera: Bruchidae) and Sitophilus granarius (L.) (Coleoptera: Curculionidae). Afr. J. Microbiol. Res. 2011, 5, 1192-1196. [CrossRef]

60. Mantzoukas, S. Pathogenicity of Fungal Agents to the MCB Sesamia nonagrioides (Lepidoptera: Noctuidae) Larvae in Laboratory Conditions. Asian. J. Bot. 2018, 1. [CrossRef]

61. Fargues, J.; Goettel, M.S.; Smits, N.; Ouedraogo, A.; Vidal, C.; Lacey, L.A.; Lomer, C.J.; Rougier, M. Variability in Susceptibility to Simulated Sunlight of Conidia among Isolates of Entomopathogenic Hyphomycetes. Mycopathologia 1996, 135, 171-181. [CrossRef]

62. Cox, P.D.; Wakefield, M.E.; Price, N.; Wildey, K.B.; Chambers, J.; Moore, D.; Aquino de Muro, M.; Bell, B.A. The Potential Use of Insect-Specific Fungi to Control Grain Storage Pests in Empty Grain Stores. Available online: https://cereals.ahdb.org.uk/ media/363584/pr341-final-project-report.pdf (accessed on 19 July 2016).

63. Zhang, T.; Reitz, S.R.; Wang, H.; Lei, Z. Sublethal Effects of Beauveria bassiana (Ascomycota: Hypocreales) on Life Table Parameters of Frankliniella occidentalis (Thysanoptera: Thripidae). J. Econ. Ėntomol. 2015, 108, 975-985. [CrossRef]

64. Pelizza, S.; Scorsetti, A.; Tranchida, M. The Sublethal Effects of the Entomopathic Fungus Leptolegnia chapmanii on Some Biological Parameters of the Dengue Vector Aedes Aegypti. J. Insect Sci. 2013, 13, 1-8. [CrossRef]

65. Dubovskiy, I.M.; Whitten, M.M.A.; Yaroslavtseva, O.N.; Greig, C.; Kryukov, V.Y.; Grizanova, E.V.; Mukherjee, K.; Vilcinskas, A.; Glupov, V.V.; Butt, T.M. Can Insects Develop Resistance to Insect Pathogenic Fungi? PLoS ONE 2013, 8, e60248. [CrossRef]

66. Cooper, W.R.; Rieske, L.K. Gall Structure Affects Ecological Associations of Dryocosmus kuriphilus (Hymenoptera: Cynipidae). Environ. Ėntomol. 2010, 39, 787-797. [CrossRef] [PubMed] 